\title{
Drop Weight Tear Test of Linepipe Materials by \\ Using Laterally Compressed Specimens*
}

\author{
By Toshio ISHIHARA, ** Jo KONDO,** Toyofumi KITADA** \\ and Toshiya AKIYAMA***
}

\section{Synopsis}

The use of pressed notch drop weight tear test (PN-DWTT) for a highly ductile linepipe steel encounters an abnormal fracture appearance, and raises difficulty in evaluating its crack arrestability of the steel. The lateral compression DWTT (LC-DWTT) has been developed to solve this problem and comparative studies with other DWTTs were carried out.

The abnormal fracture appearance can be reduced in LC-DWTT. The $85 \%$ shear area transition temperature in $L C-D W T T$ was a little higher than that in PN-DWTT but lower than that in precrack DWTT (PC-DWTT). The dynamic load-displacement characteristics of $L C$ $D W T T$ revealed that the crack initiation energy was reduced and the total absorbed energy was almost equal to the propagation energy of $P \mathcal{N}$ DWTT. On the other hand, PC-DWTT showed the lower absorbed energy because of the plastic deformation in a specimen ligament in introducing a precrack, as compared with other DWTTs.

Key words: line pipe steel; drop weight tear test; lateral compression; fracture appearance.

\section{Introduction}

The drop weight tear test with pressed notch (PNDWTT) has been adopted by API standard to define the ductile to brittle transition temperature of gas linepipe. However, a problem was encountered when applied to the recent highly tough steels such as HSLA steel or quenched and tempered steel. These steels tend to fracture at the notch root in ductile mode which is followed by brittle mode as the fracture propagates across the specimen. ${ }^{1)}$

Such an abnormal fracture appearance makes it difficult to predict the arrestability of brittle fracture. As a method to prevent the occurrence of the abnormal fracture, precrack DWTT (PG-DWTT) has been proposed by the Battelle Memorial Institute. ${ }^{2)}$ In addition, an attempt to relate the arrestability of unstable ductile fracture with absorbed energy of PG-DWTT has been started.

But PG-DWTT has an inherent drawback. Introduction of precrack leaves a large amount of plastic deformation in the specimen, which causes the deteriorating effects in both the brittle-to-ductile transition temperature ${ }^{3)}$ and the absorbed energy of DWTT. The authors have already proposed a new DWT-test method named Lateral Compression DW'TT (LG-DWTT). $\left.{ }^{4}\right)$

This report describes the comparative study be- tween LG-, PG- and PN-DWTT.

\section{Test Procedure}

\section{Drop Weight Tear Test}

Figure 1 shows the preparation of LC-DWTT specimen. ${ }^{4)}$ Figure 2 shows the apparatus for introducing lateral compression and the specimen for LGDWTT. Drop weight tear test was conducted by a pendulum type impact tester, which is instrumented to obtain a dynamic load-displacement curve during DWT-testing.

In reading a fraction of shear area in a fractured specimen, $\uparrow$ the API RP-5L3 method was adopted for all three types of DWTT in order to compare the



Ratio of Lateral compression

R.L.C. $=\frac{\text { to-t }}{\text { to }} \times 100(\%)$
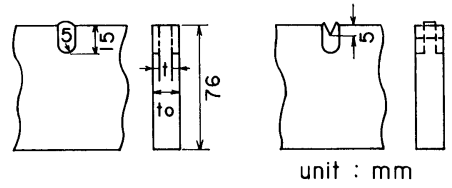

Fig. 1. Preparation of the specimen for lateral compression DWTT.

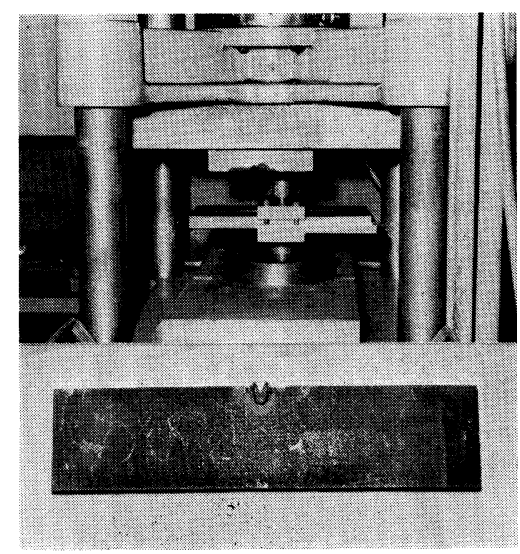

Fig. 2. Apparatus for introducing lateral compression and a specimen for testing.

\footnotetext{
* $\quad$ Presented to the 110th ISIJ Meeting, October 1985, S1379, at Niigata University in Niigata. Manuscript received on April 18, 1986; accepted in the final form on November 14, 1986. (C) 1987 ISIJ

** Fukuyama Research Laboratories, Technical Research Center, Nippon Kokan K.K., Kokan-cho, Fukuyama 721.

*** Formerly Technical Research Center, Nippon Kokan K.K. Now at Keihin Works, Nippon Kokan K.K., Minamiwatarida-cho, Kawasaki-ku, Kawasaki 210.

$+\quad$ Reference 2) has proposed that the entire fracture surface should be used in rating the shear area percent, which is in contrast to API 5L3 for the PN-DWTT.
} 
fracture mode transition behavior of one type of DWTT with another.

\section{Materials for Testing}

In total, eighteen pipes shown in Table 1 were tested. They were manufactured by UOE process from controlled rolled, quenched and tempered or accelerated cooled plates. The strength grade and the toughness varied over a wide range. For pipes thicker than $20 \mathrm{~mm}$, the thickness of specimen was reduced to $20 \mathrm{~mm}$ from both surfaces.

\section{Results}

Figure 3 shows the fracture appearance obtained by each notch type DWTT of highly tough material (upper shelf energy of Charpy test, $v E s,=26 \mathrm{kgf}-\mathrm{m}$, Sample No. J). The fracture surface in PN-DWTT shows the abnormal fracture appearance, in which ductile fracture occurred just beneath the notch root and then changed to brittle mode. In both PG- and LG-DWTT, on the other hand, such ductile fracture

Table 1. Materials tested.

\begin{tabular}{|c|c|c|c|c|c|c|c|c|c|c|}
\hline \multirow{3}{*}{ No. } & \multirow{3}{*}{ Grade } & \multicolumn{2}{|c|}{ Pipe Size } & \multirow{3}{*}{$\begin{array}{l}\text { Pro- } \\
\text { cess }\end{array}$} & \multicolumn{2}{|c|}{$\begin{array}{c}\text { Tensile } \\
\text { Test }\end{array}$} & \multicolumn{2}{|c|}{$\begin{array}{c}\text { Charpy } \\
\text { Test }\end{array}$} & \multicolumn{2}{|c|}{$\begin{array}{l}\text { PN-DWTT } \\
\text { (full thickness) }\end{array}$} \\
\hline & & $\begin{array}{l}\begin{array}{l}\text { Dia- } \\
\text { metor }\end{array} \\
\end{array}$ & \begin{tabular}{|l} 
Thick- \\
ness
\end{tabular} & & \begin{tabular}{|c|} 
YS \\
kgf/
\end{tabular} & $\begin{array}{r}\text { TS } \\
\mathrm{kgf} /\end{array}$ & $\begin{array}{r}50 \% \\
\text { FATT } \\
\end{array}$ & $\begin{array}{l}\text { Shelf } \\
\text { Energy }\end{array}$ & $\begin{array}{l}85 \% \\
\text { SATT }\end{array}$ & $\begin{array}{l}\text { Energy } \\
a t+40^{\circ} \mathrm{C}\end{array}$ \\
\hline & & $\mathrm{mm}$ & $\mathrm{mm}$ & & & & ${ }^{\circ} \mathrm{C}$ & $\mathrm{kgf-m}$ & ${ }^{\circ} \mathrm{C}$ & $\mathrm{kgf}-\mathrm{m}$ \\
\hline A & $\times 52$ & 610 & 31.8 & \multirow{3}{*}{$C R^{\prime \prime}$} & 44.3 & 54.2 & -82 & 15.4 & -12 & 1320 \\
\hline$B$ & \multirow{6}{*}{$\times 60$} & 508 & 22.2 & & 47.8 & 57.4 & -71 & 19.6 & -9 & 970 \\
\hline L & & 1067 & 15.9 & & 45.5 & 56.0 & -106 & 7.1 & -50 & 320 \\
\hline$M$ & & 1219 & \begin{tabular}{|l|}
30.2 \\
\end{tabular} & $A C^{21}$ & 46.2 & 58.1 & -96 & 40.4 & - & - \\
\hline 0 & & 610 & 22.2 & $C R$ & 45.7 & 59.0 & -106 & 7.8 & - & - \\
\hline$Q-1$ & & 1219 & 27.2 & $A C$ & 46.3 & 54.5 & -92 & 32.2 & -16 & 2280 \\
\hline$Q-2$ & & " & $"$ & $Q T^{31}$ & 49.8 & 56.2 & -104 & 33.7 & -19 & 3030 \\
\hline C & \multirow{5}{*}{$\times 65$} & 610 & 28.6 & $A C$ & 48.4 & 57.8 & -130 & 44.5 & -53 & 3770 \\
\hline D & & 523 & 23.8 & $C R$ & 49.2 & 59.5 & -90 & 27.4 & -37 & 1090 \\
\hline$L$ & & 1219 & 30.2 & $A C$ & 53.8 & 58.9 & -102 & 44.7 & -17 & 3330 \\
\hline$G$ & & 610 & 20.0 & QT & 49.6 & 63.2 & -54 & 17.7 & -17 & 1010 \\
\hline $\mathrm{P}$ & & 914 & 25.4 & $A C$ & 51.5 & 61.1 & -58 & 32.4 & - & - \\
\hline$J$ & \multirow{4}{*}{$\times 70$} & 1219 & 38.1 & QT & 58.6 & 67.1 & -30 & 26.0 & - & - \\
\hline $\mathrm{K}$ & & 610 & 19.1 & $A C$ & 52.2 & 65.7 & -103 & 48.0 & -23 & 1290 \\
\hline $\mathrm{N}$ & & 1420 & 18.7 & \multirow{4}{*}{$C R$} & 58.0 & 68.1 & -50 & 8.7 & +4 & 510 \\
\hline$F$ & & $"$ & 26.9 & & 53.3 & 63.5 & -96 & 9.3 & -15 & 720 \\
\hline $\mathrm{H}$ & \multirow[t]{2}{*}{$\times 80$} & " & 20.0 & & 60.3 & 69.7 & -104 & 22.2 & -26 & 780 \\
\hline I & & " & 18.7 & & 62.6 & 74.5 & -82 & 22.8 & -9 & 810 \\
\hline
\end{tabular}

1) Controlled rolled plate 2) Accelerated cooled plate

3) Quenched and tempered plate did not occur.

But the perfect prevention is difficult even though LG-DWTT is adopted. For extremely highly tough pipes such as Sample No. E in Table 1 (vEs= $44.7 \mathrm{kgf}-\mathrm{m})$, for example, the abnormal fracture appearance was observed in all types of DWTT.

Figure 4 demonstrates the effect of RLG on absorbed energy at the temperature showing $100 \%$ shear fracture in LG-DWTT. The absorbed energy decreases with increasing RLG, and it levels off to give a constant value unique to each material at each temperature. The required RLG for obtaining a constant value of absorbed energy (LC*) has a tendency to increase with an increase in absorbed energy of PN-DWTT. Figure 5 also shows that LG* reaches almost constant value when the value of ${ }_{\mathrm{PN}} E t / A_{\mathrm{PN}}$ is large enough. In the case of recent linepipe steels with extremely high ductility, $25 \%$ of RLG value is insufficient but $50 \%$ of RLG is enough to give a constant absorbed energy in the range of materials listed in Table 1.

Figure 6 shows typical transition curves of absorbed energy and a fraction of shear area for each DWTT method. The transition curves of LG-DWTT are located between those of PC- and PN-DWTT.

Figure 7 summarizes the relation between $85 \%$ SATT by each type of DWTT at $+40^{\circ} \mathrm{C}$, which shows the same tendency as in Fig. 5.



Fig. 4. Relation between the absorbed energy of LCDWTT and the ratio of lateral compression.



Fig. 3. Typical fracture appearances (tested at $+20^{\circ} \mathrm{C}$, Sample J).



Fig. 5. Change in critical value of lateral compression (LG*) with absorbed energy of PN-DWTT. 




Fig. 6. Comparison between transition curves of PN-, PCand LG-DWTT.

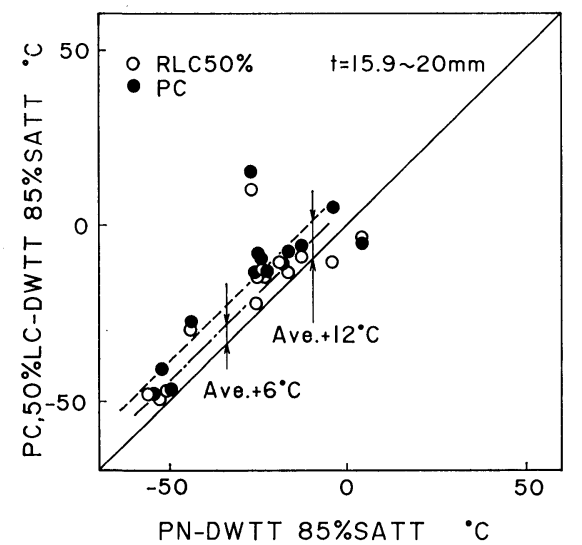

Fig. 7. Relation of $85 \%$ SATT between PN-, PG- and LC-DWTT.

\section{Discussion}

\section{Absorbed Energy in LC-DWTT}

Figure 8 illustrates dynamic load-deflection curve during fracture at $+40^{\circ} \mathrm{C}$ for each DWTT. Absorbed energy corresponds to the area enclosed by each curve. For convenience, the crack initiation energy in PN-DWTT was defined as the area before reaching the peak load of the curve of PN-DWTT, and also the crack propagation area as the area beyond the peak load.5)

Then the following can be seen in the curve of LG-DWTT:

(1) The energy required for crack initiation (area before reaching the peak load) decreases with an increase of RLG but does not change when the amount of RLG becomes larger than $50 \%$. This results correspond to Fig. 4.

(2) In crack propagation area, the load-deflection curve of PN-DWTT matches that of LG-DWTT.

In the case of PG-DWTT, the following is seen.

(1) The curve before reaching the peak load in PG-DWTT almost equals that in LG-DWTT laterally compressed up to $50 \%$.

(2) The curve for crack propagation area in PG-DWTT is located below those of other types of

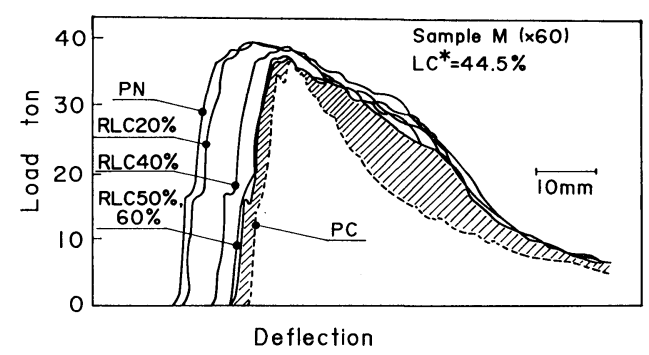

Fig. 8. Examples of dynamic load-deflection curve for various types of DWTT.

\section{DWTT}

The difference of curves in a propagation area is attributed to the plastic deformation of ligament caused by precracking. Figure 9 demonstrates each dynamic load-deflection curve during PN-DWTT after a tensile strain of up to $10 \%$ (Tensile-PNDWTT) is applied. It is seen in this figure that the propagation portion in the curve shifts downward when tensile strain is increased, which is the same trend as that of PG-DWTT. This result indicates that the absorbed energy of PG-DWTT is affected by plastic deformation of the ligament caused by precracking.

Figure 10 shows a correlation of the crack propagation energy per unit area in PN-DWTT ( ${ }_{\mathrm{PN}} E p /$ $\left.A_{\mathrm{PN}}\right)$ with total absorbed energies of PG- and LGDWTT $\left({ }_{\mathrm{PC}} E t / A_{\mathrm{PC}},{ }_{\mathrm{LC}} E t / A_{\mathrm{LC}}\right)$. Figures 8 and 10 indicate that the absorbed energy for LG-DWTT $(\mathrm{RLG} \geqq 50 \%)$ is almost equal to the propagation energy of PN-DWTT.

\section{2. $85 \%$ SATT of LC-DWTT}

As shown in Fig. 7, $85 \%$ SATT of LG-DWTT is higher than that of PN-DWTT but lower than that of PG-DWTT. The reason why $85 \%$ SATT of LG-DWTT is higher than that of PN-DWTT seems to be a higher sensitivity to a brittle fracture of the notch in LG-DWTT. Iwasaki et al. ${ }^{1)}$ reported that $85 \%$ SATT lowered as the root radius of the Vnotch in PN-DWTT increased. It is considered that the lateral compression makes the material in the vicinity of notch including a notch root embrittle and consequently provides the same effect as reducing the radius of the notch root.

On the other hand, the fact that the $85 \%$ SATT of PG-DWTT is higher than that of LG-DWTT mainly comes from the embrittlement by plastic deformation in the specimen ligament during pre-cracking process. This was confirmed through the investigation which showed that $85 \%$ SATT of Tensile-PNDWTT rises with tensile prestrain in specimens as shown in Fig. 11.

Moreover, it is important that the rise in $85 \%$ SATT of PG-DWTT from that of PN-DWTT $\left(\Delta T_{2}\right)$ is even larger than that of Tensile-PN-DWTT (tensile prestrain is $10 \%)\left(\Delta T_{1}\right)$, where $10 \%$ of tensile strain almost equals a uniform elongation of this material. This fact may suggest that the sensitivity of precracked notch to brittle fracture is higher than that of pressed notch, and as a result, the $85 \%$ SATT of PG-DWTT 


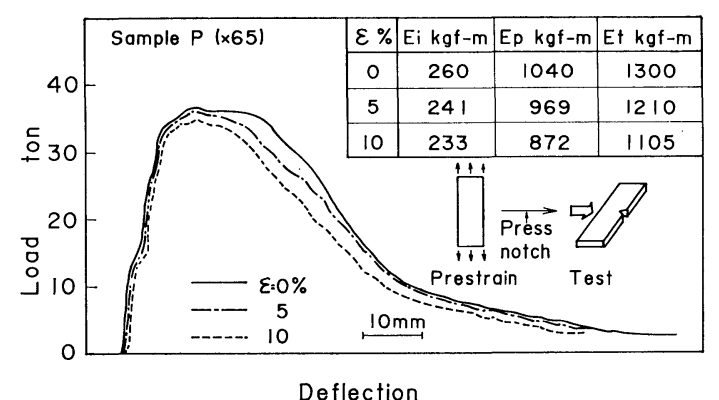

Fig. 9. Effect of tensile prestrain on dynamic load-deflection curve of PN-DWTT.

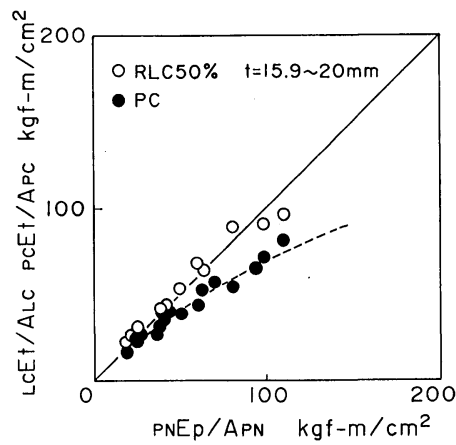

Fig. 10. Relation between total absorbed energies of LCand PG-DWTT $v s$. the propagation energy of PN-DWTT.

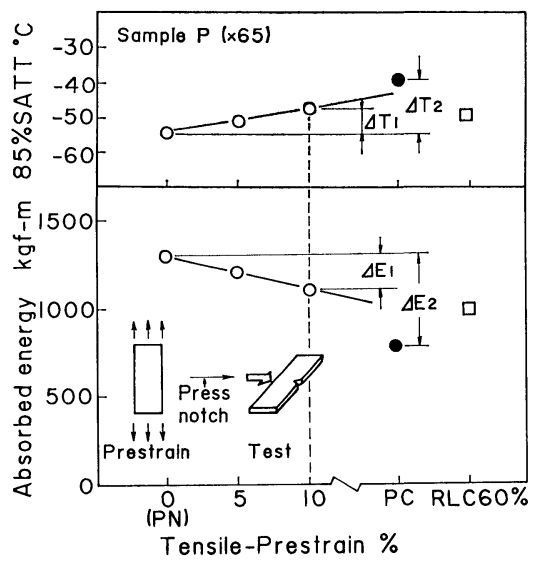

Fig. 11. Effect of tensile prestrain on absorbed energy and $85 \%$ SATT of DWTT.

may be higher than that of $10 \%$ Tensile-PN-DWTT. Besides, the strain beneath a precracked notch almost equals fracture strain, which is larger than the uniform elongation. So the degree of embrittlement near the notch will be stronger in PG-DWTT than in Tensile-PN-DWTT. This status will also rise the $85 \%$ SATT of PG-DWTT.

In order to confirm the phenomenon, a more careful investigation, such as the difference of deformation mode between plastic bending and uniaxial tension and acuity of each notch, will be required.

\section{Evaluation of $L C-D W T T$}

PG-DWTT is effective to reduce abnormal fracture appearance in PN-DWTT. However, it has some problems, which are caused by plastic deformation introduced during precracking, in estimating arrestability of both brittle fracture (85\% SATT approach) and unstable shear fracture (absorbed energy approach).

On the other hand, LG-DWTT, which can prevent the undesired abnormal fracture in a specimen, does not show such a problem as the abnormal fracture in PG-DWTT. Moreover, a process for introducing a notch is easier in LG-DWTT than in PG-DWTT which requires careful treatment in introducing a precrack.

As a result, LG-DWTT is considered to be superior to others. But the final judgment must be made through the comparison which is the most predictable for fracture arrestability of actual pipeline. So, further investigation is necessary to relate the characteristics of each DWTT with fracture behavior in a full scale burst test.

\section{Conclusion}

The $85 \%$ shear area transition temperature and absorbed energy in lateral compression DWTT were studied in comparison with those of PG- and PNDWTT and the following was concluded.

(A) Gharacteristics of LG-DWTT

(1) The absorbed energy decreases and $85 \%$ SATT rises with the increase in the extent of lateral compression, but they reach a constant value unique to each material when the extent exceeds about $50 \%$.

(2) Both absorbed energy and $85 \%$ SATT are between those of PN- and PG-DWTTs. In particular, the absorbed energy of LG-DWTT (RLG $\geqq 50 \%$ ) is almost equal to the propagation energy of PNDWTT.

(B) Evaluation of LG-DWTT

(1) LG-DWTT can considerably suppress the occurrence of abnormal fracture appearance in the specimen which may occur in PN-DWTT for highly tough materials. The degree of improvement is equivalent to PG-DWTT.

(2) When compared with LG-DWTT, the PGDWTT has a problem of strain embrittlement due to plastic bending. The LG-DWTT does not have such a problem.

As a result, LG-DWTT can eliminate the problems of both PN- and PG-DWTT, and it will be more predictable of the fracture arrestability of linepipe. Further investigation such as a full scale burst test for linepipe may be required to confirm the applicability of LG-DWTT.

\section{REFERENCES}

1) N. Iwasaki, T. Yamaguchi and T. Taira: Mech. Work. Steel Processing, XIII, AIME, New York, (1975), 294.

2) G. M. Wilkowski and R.J. Eiber: " Procedure for Conducting the Static Precrack Drop Weight Tear Test on Line Pipe", API Annual Meeting, Houston, Jan. 1979.

3) T. Taira, K. Ume, T. Ishihara and H. Ichinose: Trans. ISIJ, 20 (1980), B610.

4) T. Akiyama, Y. Hirose and N. Urabe: Trans. ISIJ, 25 (1975), 1267.

5) K. Besho, A. Inami, Y. Sumitomo and M. Tsukamoto: Tetsu-to-Hagané, 68 (1982), S1326. 